\title{
Acyclic cucurbit[n]uril-type molecular container enables systemic delivery of effective doses of albendazole for treatment of SK-OV-3 xenograft tumors
}

\author{
Gaya Hettiarachchi ${ }^{\dagger}$, Soumen K Samanta ${ }^{\ddagger}$, Shane Falcinelli ${ }^{\dagger}$, Ben Zhang $^{\ddagger}$, Damien \\ Moncelet ${ }^{\dagger}$, Lyle Isaacs ${ }^{\ddagger},{ }^{*}$, and Volker Briken ${ }^{\dagger},{ }^{*}$ \\ tUniversity of Maryland, Department of Cell Biology and Molecular Genetics, College Park, MD \\ 20742 \\ FUniversity of Maryland, Department of Chemistry and Biochemistry, College Park, MD 20742
}

\begin{abstract}
Approximately, 40-70\% of active pharmaceutical ingredients (API) are severely limited by their extremely poor aqueous solubility and consequently there is a high demand for excipients that can be used to formulate clinically relevant doses of these drug candidates. Here, proof-of-concept studies demonstrate the potential of our recently discovered acyclic cucurbit[n]uril-type molecular container Motor1 (M1) as a solubilizing agent for insoluble drugs. M1 did not induce significant rates of mutations in various Salmonella typhimurium test strains during the Ames test, suggesting low genotoxicity. M1 also has low risk of causing cardiac toxicity in humans since it did not inhibit the human Ether-á-go-go-Related Gene channel as tested on transfected CHO cell lines via patch clamp analysis. Albendazole (ABZ) is a widely used anti-helminthic agent but that has also shown promising efficacy against cancerous cells in vitro. However, due to its low aqueous solubility (2.7 micromolar) and poor pharmacokinetics, ABZ is clinically limited as an anti-cancer agent. Here we investigated the potential of M1 as a solubilizing excipient for ABZ formulation. A pharmacokinetic study indicated that ABZ escapes the peritoneal cavity resulting in $78 \%$ absolute bioavailability while its active intermediate metabolite, albendazole sulfoxide, achieved $43 \%$ absolute bioavailability. The daily dosing of $681 \mathrm{mg} / \mathrm{kg} \mathrm{M} 1$ complexed with $3.2 \mathrm{mg} / \mathrm{kg}$ of ABZ for 14 days did not result in significant weight loss or pathology in Swiss Webster mice. In vivo efficacy studies using this M1•ABZ inclusion complex showed significant decreases in tumor growth rates and increases in survival of mice bearing SK-OV-3 xenograft tumors. In conclusion, we provide substantial new evidence demonstrating that M1 is a safe and efficient excipient that enables in vivo parenteral delivery of poorly water-soluble APIs.
\end{abstract}

\section{Graphical Abstract}

\footnotetext{
“Corresponding Authors. vbriken@umd.edu. 'Lisaacs@umd.edu.
}

The authors declare no competing financial interest. 


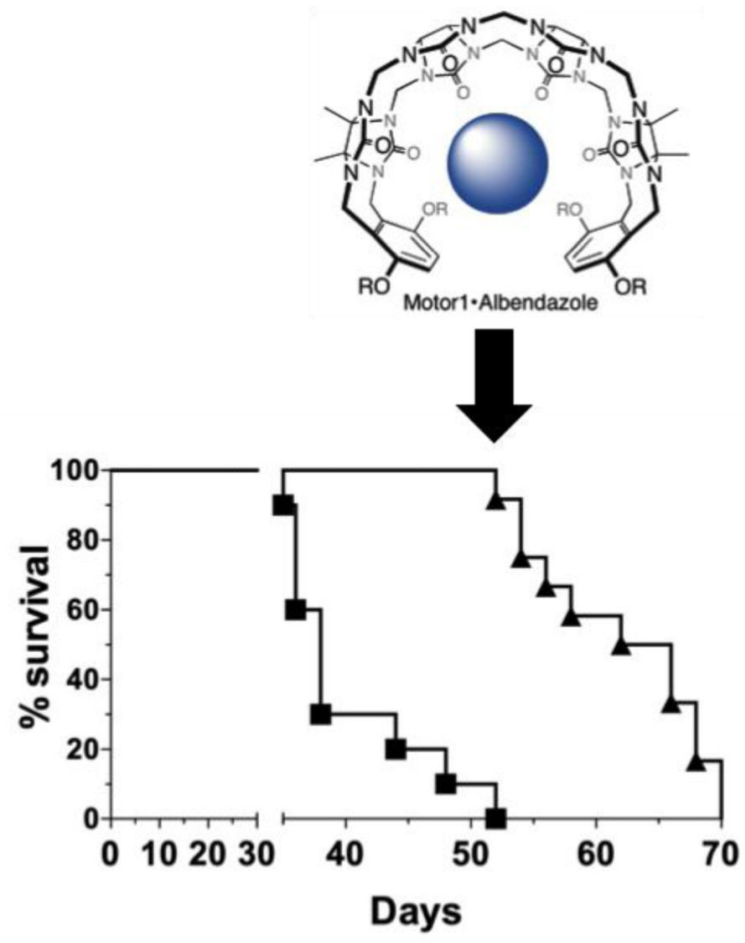

\section{Keywords}

Cucurbit[n]uril; Albendazole; Solubility; Cancer; Drug delivery; excipient; molecular container

\section{INTRODUCTION}

The low aqueous solubility of drug candidates is a significant hurdle in many drug development projects. ${ }^{1,2}$ Approximately $40-70 \%$ of all new active pharmaceutical ingredients (API) can be categorized into the Biopharmaceutics Classification System (BCS) class II, as having low aqueous solubility but high intestinal permeability. ${ }^{1,2}$ To address this problem, there is a demand for solubilizing agents that can be used to formulate clinically relevant doses of these APIs. For example, there are a variety of solubilizing agents currently used in the market or during drug development like liposomes, dendrimers and surfactants such as CremophorEL ${ }^{\circledR}{ }^{3}$

Amongst molecular container compounds, the cyclodextrins (CD) are the most widely studied as solubilizing excipients for insoluble drugs. ${ }^{4}$ This research has led to the development of Captisol ${ }^{\circledR}$ (sulfobutylether-beta-cyclodextrin) which is now used as an excipient for marketed drugs like Nexterone ${ }^{\circledR}$ (life threatening heart arrhythmia disorders), VFend ${ }^{\circledR}$ (antifungal), and Abilify ${ }^{\circledR}$ (antipsychotic). ${ }^{5}$ Despite the great success of Captisol®, its ability to solubilize insoluble drugs is limited by its moderate binding affinities which makes it less successful for drugs with inherent solubility in the low micromolar range. However, it should be clear that no single container compound can solubilize the wide variety of APIs due to the inherent binding preferences of each different container. 
Accordingly, there exists a need for new classes of containers that can solubilize a broader range of insoluble drugs.

In the past 15 years, a new class of molecular container compounds known as cucurbit[n] urils $(\mathrm{CB}[\mathrm{n}], \mathrm{n}=5,6,7,8,10)$ have been developing rapidly. ${ }^{6-11} \mathrm{CB}[\mathrm{n}]$ containers bind more strongly to guest (e.g. drugs) compounds than cyclodextrins, ${ }^{12-16}$ and have therefore been considered for use in a variety of drug solubilization and delivery applications. ${ }^{17-34}$ Of these five $\mathrm{CB}[\mathrm{n}]$ containers, $\mathrm{CB}[7]$ is most attractive as a solubilizing excipient because of its good solubility in pure water (reported as $5 \mathrm{mM}$ by $\mathrm{Nau}^{10}$ and 20$30 \mathrm{mM}$ by $\mathrm{Kim}^{35}$ ). We have recently introduced acyclic $\mathrm{CB}[\mathrm{n}]$ type molecular containers $^{36,37}$ that possess a confluence of properties that we believe make them well suited as attractive alternatives to cyclodextrins and $\mathrm{CB}[\mathrm{n}]$ as solubilizing excipients for insoluble drugs. The chemical structure of a promising acyclic $\mathrm{CB}[\mathrm{n}]$-type molecular container, Motor1 (M1), is shown in Figure 1. Advantageously, acyclic M1 is highly soluble in water $(105 \mathrm{mM})$ and is capable of adjusting its cavity size to accommodate a variety of different guest sizes. M1 is capable of significantly increasing the aqueous solubility of numerous APIs, including many that could not be solubilized with HP- $\beta-C D .{ }^{36,} 37$ In contrast, macrocyclic $\mathrm{CDs}$ and $\mathrm{CB}[\mathrm{n}]$ cannot easily adjust their cavity size to accommodate different sized guests. Additionally, the internal molecular recognition surfaces of acyclic $\mathrm{CB}[\mathrm{n}]$ can be tailored by synthetic modifications. In a series of papers, we have explored the influence of the nature of the solubilizing groups, ${ }^{38}$ the aromatic walls, ${ }^{37}$ and the length of the central glycoluril oligomer ${ }^{39}$ on the solubilizing ability of acyclic $\mathrm{CB}[\mathrm{n}]$-type containers. We have found that acyclic $\mathrm{CB}[\mathrm{n}]$ display higher binding affinity (range: $10^{3}-10^{6} \mathrm{M}^{-1}$ ) than HP- $\beta$-CD (range: $10^{2}-10^{4} \mathrm{M}^{-1}$ ) toward a panel of 19 insoluble drugs which means that lower concentrations of acyclic $\mathrm{CB}[\mathrm{n}]$ are needed to formulate a given concentration of drug. ${ }^{37}$ Of relevance to the work reported herein are the binding constants reported for the HP- $\beta$-CD•albendazole $\left(\mathrm{K}_{\mathrm{a}}=5.4 \times 10^{3} \mathrm{M}^{-1}\right)$, M1 albendazole $\left(\mathrm{K}_{\mathrm{a}}=5.1 \times 10^{4} \mathrm{M}^{-1}\right)$, and $\mathrm{CB}$ [7] $\bullet$ albendazole complexes $\left(\mathrm{K}_{\mathrm{a}}=6.5 \times 10^{4} \mathrm{M}^{-1}\right.$ for $\mathrm{ABZ} ; 2.4 \times 10^{7} \mathrm{M}^{-1}$ for $\left.\mathrm{ABZH}^{+}\right){ }^{24}$ The generally higher values of $\mathrm{K}_{\mathrm{a}}$ seen for $\mathrm{CB}$ [7] $\bullet$ guest complexes ${ }^{12,13,15}$ can be advantageous in that slow drug release has been demonstrated to improve the bioactivity of cisplatin due to a pharmacokinetic effect, ${ }^{18}$ but could be a disadvantage if the CB[7]•drug complex is cleared from the body before release occurs. Previously, we have shown that M1 displays low toxicity in both in vitro assays and in vivo maximal tolerated dose studies. We have also previously demonstrated the ability of M1 to increase the solubility of paclitaxel and thereby increase its in vitro bioactivity. ${ }^{36}$ The confluence of physical and molecular recognition properties of M1 which are distinct from those of HP- $\beta-\mathrm{CD}$ and $\mathrm{CB}$ [7], has prompted us to continue our investigation of the potential of M1 as a solubilizing excipient for in vivo studies.

M1 can be used to solubilize a variety of APIs across various therapeutic fields. We conducted a proof-of-concept study using a cancer model system because cancer is a leading cause of mortality worldwide with approximately 8.2 million fatalities in $2012 .{ }^{40}$ As a result, extensive efforts have been focused on the discovery and development of new cancer therapies. Alternatively, due to the costs of drug development, more recent studies have investigated repurposing of drugs for the use in cancer therapy. For example, Albendazole 
(ABZ; Figure 1) is an anti-helminthic that targets rapidly replicating cells by binding $\beta$ tubulin, inhibiting microtubule formation and thus halting cell division. ${ }^{41,42} \mathrm{ABZ}$ is currently being studied for use as an anti-cancer agent. ${ }^{43,44}$ Nevertheless, its broader application is limited by its low solubility in water $(2.7 \mu \mathrm{M})$ restricting its use for parenteral delivery and low permeability in the GI-tract, which precludes enteral route of administration for systemic delivery to be effective. ${ }^{45}$ This limitation and the fact that ABZ is already approved for use in humans by the United States Food and Drug Administration (FDA) makes ABZ a compelling candidate for formulation with M1 in order to perform proof-of-concept studies for the use of M1 as a novel API excipient to enable parenteral delivery of ABZ for cancer treatment.

\section{EXPERIMENTAL SECTION}

\section{Materials}

Trypsin (Gibco® 15090-046) was purchased from Gibco ${ }^{\circledR}$ and EDTA (FisherScientific 02793-500) was purchased from Fisher Scientific. Albendazole (ABZ, VWR Catalog \# 1012553), Albendazole sulfoxide (ABZSO, Sigma-Aldrich, Catalog \# 19953-25g), and Albendazole sulfone (ABZSO2, Alfa Aesar, Catalog \# AAH25917-03) were obtained from commercial sources. Staurosporine (Sigma-Aldrich S6942) was purchased from SigmaAldrich. M1 was synthesized as described previously. ${ }^{36}$

\section{Formulation of $\mathrm{ABZ}$}

The formulation of ABZ as the M1 ABV complex (containing $60 \mathrm{mM} \mathrm{M} 1$ and $1.5 \mathrm{mM}$ ABZ) is described in detail in the Supporting Information. In brief, a solution of M1 (60 $\mathrm{mM}$ ) is stirred with solid $\mathrm{ABZ}$ for $12 \mathrm{~h}$ after which it is centrifuged and filtered through a $0.2 \mu \mathrm{m}$ filter. The concentrations of M1 and ABZ are determined by $1 \mathrm{H}$ NMR integration versus added benzene-1,3,5-tricarboxylic acid $(1.00 \mathrm{mM})$ as an internal standard. Despite the fact that M1 and ABZ form a 1:1 non-covalent complex (Supporting Information) it is necessary to use a large excess of M1 because of the low inherent solubility of ABZ (2.7 $\mu \mathrm{M})$ and the relatively weak binding constant $\left(\mathrm{K}_{\mathrm{a}}=1.5 \times 10^{4} \mathrm{M}^{-1}\right.$ in $50 \mathrm{mM} \mathrm{DCl}$ in $\mathrm{D}_{2} \mathrm{O}$, Supporting Information) for the M1•ABZ complex as described by the theory of phase solubility diagrams $37,46,47$.

\section{Bacterial Culture}

Strains were obtained as part of the Salmonella Mutagenicity Test Kit (MOLTOX® 31100.2). Flasks were inoculated with the four Salmonella typhimurium strains (TA135, TA1537, TA98, \& TA100) and incubated at $37^{\circ} \mathrm{C}, 150 \mathrm{rpm}$ for 16 hours. The cultures were serially diluted and plated to determine the bacterial titer for each culture.

\section{AMES Test}

The Salmonella Mutagenicity Test Kit was used to assess the mutagenic potential of the compounds according to the procedure provided by the vendor. Positive controls included known mutagens: Sodium Azide (1.5 $\mu \mathrm{g} / \mathrm{plate}$; TA1535 and TA100), Daunomycin (6 $\mu \mathrm{g} /$ plate; TA 1537), ICR 191 Acridine (1 $\mu \mathrm{g} / \mathrm{plate}$; TA98), and 2-Aminoanthracene (10 $\mu \mathrm{g} /$ plate; all $+\mathrm{S} 9$ samples). Negative controls consisted of the solvent used to solubilize the test 
material (water, DMSO, and phosphate buffer). Each set of experiments was also performed with or without rat liver S9 fraction in the top agar layer in order to address the potential mutagenicity of metabolites created in the liver. A positive result is determined by comparing the number of reverting colonies obtained after treatment with the test compound with the number of spontaneous revertants for each S. typhimurium strain used. A compound is thought to be mutagenic if the test numbers exceed twice the number of spontaneous colonies. In this instance, a ratio of 2 and above for M1/solvent control would indicate a positive result (e.g. mutagenicity).

hERG Assay

The human Ether-á-go-go-Related Gene (hERG) assay was performed by Apredica ${ }^{\circledR}$, a Cytoprex company. This automated patch clamp study was conducted using Chinese Hamster Ovary (CHO) transfected with the hERG ion channel. M1 concentrations up to 25 $\mu \mathrm{M}$ were used along with quinidine as a positive control. The ion channel current was tested before and after the test compounds were added to the cells. The data is normalized with respect to the current in each well before the compound is added to the patch clamp.

\section{Cell Culture}

SK-OV-3 cells (ATCC\# HTB-77) cells were grown in McCoy's 5A Media (ATCC\# 302007) with $10 \%$ Fetal calf serum (FCS; Hyclone) and 1\% Penicillin/Streptomycin (Pen/ Strep; CellGro® $30-001-\mathrm{CI})$ at $37^{\circ} \mathrm{C}$ and $5 \% \mathrm{CO} 2$.

\section{In vitro Bioactivity Study}

SK-OV-3 cells were plated in a 96 well plate at $5 \times 10^{5}$ cells/well. Cells were allowed to adhere overnight and were then treated with increasing concentrations of M1•ABZ for $24 \mathrm{~h}$. Cell Death ELISA® (Roche 11544675001) was performed according to the instructions of the vendor. Data from six samples $(n=6)$ were combined and normalized relative to $100 \%$ cell death induced by staurosporine according to Equation 1. EC50 value was calculated via nonlinear regression analysis using GraphPad Prism 6 software.

$$
\frac{\text { sample }(\text { abs })}{\text { Staurosporine }(\text { ave abs })} \times 100=\% \text { apoptosis }
$$

\section{Animal Studies}

Animal studies were conducted at the University of Maryland, College Park, MD under the approval and guidance of Institutional Animal Care and Use Committee (IACUC; protocol \#R-14-02).

\section{Pharmacokinetic Study}

A total of 40 outbred Swiss Webster mice (NCI; strain code 551) were randomly separated into 8 groups of 5 mice. At each of the selected 8 time points (5, 15, 30 min and 2, 4, 8, 16, $24 \mathrm{~h}$, blood was harvested by cardiac puncture from mice that were previously injected once with $\mathrm{M} 1 \bullet \mathrm{ABZ}$ (681 and $3.2 \mathrm{mg} / \mathrm{kg}$ ) through the intraperitoneal route. Plasma was purified from the blood samples by centrifugation at $2000 \times \mathrm{g}$ for $15 \mathrm{~min}$. Plasma concentrations of 
$\mathrm{ABZ}, \mathrm{ABZSO}$ and $\mathrm{ABZSO}_{2}$ over time were measured using HPLC (Microsorb-MV 100-5 $\mathrm{C} 18$ column; $5 \mu \mathrm{m}, 250 \times 4.6 \mathrm{~mm}$ ). This procedure was repeated for 40 additional mice using the intravenous route of administration. All time points and other experimental parameters were the same as mentioned above.

\section{Plasma Extraction}

A Strata $\mathrm{NH}_{2}(55 \mu \mathrm{m}, 70 \AA$ ) ion exchange resin column (Phenomenex, Product number 8BS009-EAK) was preconditioned by rinsing with $\mathrm{NaOAc}$ buffered $\mathrm{H}_{2} \mathrm{O}(1 \mathrm{~mL}, 20 \mathrm{mM}, \mathrm{pH}$ 3.0). An aliquot of each plasma sample $(150 \mu \mathrm{L})$ was loaded onto the column. The resin was then washed with $1.0 \mathrm{~mL}$ of a solution of $0.1 \%$ formic acid in $\mathrm{MeOH}: \mathrm{H}_{2} \mathrm{O}(9: 1)$. The eluent was evaporated to dryness and resuspended in HPLC mobile phase (vide supra). The sample was vortexed $(5 \mathrm{~min})$ and then centrifuged $\left(2000 \mathrm{rpm}, 5 \mathrm{~min}, 20^{\circ} \mathrm{C}\right)$. The supernatant was collected and was analyzed by HPLC as described below.

\section{High Performance Liquid Chromatography (HPLC) Analysis}

The HPLC analysis was performed using a Microsorb-MV 100-5 C18 column (5 $\mu \mathrm{m}, 250 \times$ $4.6 \mathrm{~mm}$ ) on a Varian ProStar HPLC system. The mobile phase contained $1.3 \% \mathrm{NEt}_{3}$ in a mixture of $\mathrm{H}_{2} \mathrm{O}: \mathrm{MeOH}: \mathrm{CH}_{3} \mathrm{CN}$ (50:34:16) whose $\mathrm{pH}$ was adjusted to 3.2 by using $85 \%$ orthophosphoric acid. The injection volume was $20 \mu \mathrm{L}$ ( $20 \mu \mathrm{L}$ injection loop was used) and the analytes were detected at $295 \mathrm{~nm}$ wavelength using a variable wavelength UV/Vis detector. Each sample was run for $15 \mathrm{~min}$ with flow rate of $1.00 \mathrm{~mL} / \mathrm{min}$. Under these conditions, $\mathrm{ABZSO}, \mathrm{ABZSO}_{2}$ and $\mathrm{ABZ}$ were detected at 4.5, 5.8 and 13.6 min respectively. The peaks for $\mathrm{ABZ}, \mathrm{ABZSO}$, and $\mathrm{ABZSO}_{2}$ in the HPLC spectra were integrated using the software supplied by the instrument manufacturer and converted into concentrations in $\mu \mathrm{g} / \mathrm{mL}$ using calibration curves that had been created previously (Supporting information, Figure S1-S4 and Tables S1-2).

\section{Maximum Tolerated Dose (MTD) Study}

A total of 35 female, outbred Swiss Webster mice (NCI; strain code 551) were injected daily by the intraperitoneal (IP) route for 14 days and then observed daily for an additional two weeks. Mice were dosed by weight $(10 \mathrm{~mL} / \mathrm{kg})$. Treatment groups were Untreated, M1 $(681 \mathrm{mg} / \mathrm{kg})$, and increasing concentration of ABZ in M1 (0.5, 1.4, 2.3 and $3.2 \mathrm{mg} / \mathrm{kg})$. Each treatment group consisted of 7 mice. Mice were visually observed and weight was monitored every other day as an indication of health.

\section{In Vivo Efficacy Study}

SK-OV-3 cells were prepared at $1 \times 10^{7}$ cells $/ \mathrm{mL}$ in $33 \%$ Matrigel ${ }^{\circledR}$ Matrix (Corning 354248) solution. A total of 40 female, athymic NCr-nu/nu (NCI; strain code 553) were injected subcutaneously over the neck with $100 \mu \mathrm{L}$ of cell solution $\left(1 \times 10^{6}\right.$ cells $)$. In the first study, treatment began once tumors had reached a volume of $250-300 \mathrm{~mm}^{3}$. Mice were dosed via IP route with M1 $(681 \mathrm{mg} / \mathrm{kg}), \mathrm{M} 1 \bullet \mathrm{ABZ}(3.2 \mathrm{mg} / \mathrm{kg})$ once daily, and M1•ABZ $(3.2 \mathrm{mg} / \mathrm{kg}$ ) twice daily for 50 consecutive days. The second experiment involved 35 consecutive days of M1 (681 mg/kg) and M1•ABZ (3.2 mg/kg) dosing. Treatment started when tumors were at a volume of $100-150 \mathrm{~mm}^{3}$. Both studies included an untreated control 
group and used 10 mice per experimental group. Mice were dosed by weight $(10 \mathrm{~mL} / \mathrm{kg})$. Mice were sacrificed at either $20 \%$ weight loss or if tumor volume reached $1500 \mathrm{~mm}^{3}$.

\section{Statistics}

GraphPad Prism 6 was used to calculate statistical significance, slopes of fitted lines and $\mathrm{EC}_{50}$ and $\mathrm{IC}_{50}$ values via nonlinear regression analysis. Student $t$-test was performed unless stated otherwise. Log-rank test was used to analyze survival curves. The pharmacokinetic parameters $\mathrm{C}_{\max }, \mathrm{t}_{\max }$, and area under the curve (AUC) values were also calculated using GraphPad Prism 6. *p=0.01-0.05, ** $\mathrm{p}=0.001-0.1, * * * \mathrm{p}<0.001$.

\section{RESULTS}

M1 is a novel acyclic $\mathrm{CB}[\mathrm{n}]$-type compound that has been shown to significantly increase the solubility of many APIs and was found to be non-toxic in some in vitro and in vivo toxicity studies. ${ }^{36,48}$ Due to these promising results, here, we continued to investigate the potential use of M1 as a solubilizing agent for in vivo delivery of the anti-cancer agent ABZ (Figure 1).

\section{In vitro M1 biocompatibility studies}

Salmonella typhimurium Mutagenicity Assay-Initial studies on M1 have established acute safety in human cell lines and the mouse model. ${ }^{36}$ In order to expand the scope of the M1 toxicology analysis, we assessed the mutagenicity of the compound using the reverse mutation assay (Ames test). This assay utilizes four different S. typhimurium strains, which possess unique G-C mutations within the histidine operon. This assay also employs rat liver enzyme fractions (S9) to model the interaction of test compounds with liver enzymes and to investigate the mutagenic potential of metabolites. ${ }^{49}$

The S. typhimurium strain TA1535 contains a T to C missense mutation in the his Gene (hisG46) leading to a leucine to proline amino acid substitution. With the reversal of this mutation, TA1535 can detect compounds that cause base-pair mutations. M1 (0.037 mg/ plate) incubated without the $S 9$ fraction, resulted in the largest number of revertant TA1535 colonies ( $12 \pm 5$ colonies, Table 1$)$. When incubated with the S9 fraction, M1 $(0.330 \mathrm{mg} /$ plate) resulted in $11 \pm 1$ revertant colonies. The M1/solvent control ratio was found to be 1.33 (-S9) and $1.22(+$ S9). The positive controls for this strain showed 232 revertant colonies for the sodium azide (-S9) treatment and 27 colonies for the 2-aminoanthracene (+S9) samples.

The TA1537 strain detects compounds that induce $\mathrm{a}+1$ frameshift mutation on the his $\mathrm{C}$ gene (hisC3076). This allows frameshift mutagens to be detected. Using this strain, the highest number of colonies ( 6 colonies) were seen at $0.037 \mathrm{mg} / \mathrm{plate}$ of $\mathrm{M} 1$ without the S9 fraction resulting in a ratio of 1 . Likewise, when incubated with the $S 9$ fractions, the highest number of colonies $(5 \pm 1)$ were observed at $0.11 \mathrm{mg} /$ plate of M1, resulting in a ratio of 1.25. Positive controls produced 91 revertant colonies when treated with ICR 191 Acridine (-S9) and 122 colonies with 2-aminoanthracene (+S9).

The TA98 strain detects +1 frameshift mutation on the his D gene (his D3052) and also contains the pkM101 plasmid, which increases the sensitivity of the strain to mutagenic 
compounds. For this strain, results indicated a ratio of 1.27 at an M1 concentration of 0.11 $\mathrm{mg} / \mathrm{plate}$ ( $23 \pm 4$ colonies) without the $\mathrm{S} 9$ fraction. With the $\mathrm{S} 9$ fraction, $0.012 \mathrm{mg} / \mathrm{plate}$ of M1 (16 \pm 8 colonies) resulted in a ratio of 1.06. Furthermore, the positive controls for the strain resulted in 361 revertant colonies when treated with Daunomycin (-S9) and 1084 colonies with 2-aminoanthracene (+S9) incubation.

Finally, TA100 (Table 1) contains the same mutation as TA1535 plus the pk M101 plasmid. Incubation with this strain resulted in a ratio of 1.25 for a $\mathrm{M} 1$ concentration of $0.11 \mathrm{mg} / \mathrm{plate}$ without the S9 fraction ( $39 \pm 1$ colonies). With the $\mathrm{S} 9$ fraction, M1 at $1 \mathrm{mg} / \mathrm{plate}(70 \pm 2$ colonies) resulted in a ratio of 1.59 . The positive controls yielded 167 revertant colonies with sodium azide (-S9) and 1345 colonies with 2-aminoanthracene (+S9) incubation.

The evaluation of M1 for concentrations up to $1 \mathrm{mg} /$ plate using the Ames test revealed revertant colony numbers that did not exceed double the number of colonies induced by the solvent control. Consequently, the Ames test conducted using four different S. typhimurium strains and an M1 concentration of up to $1 \mathrm{mM}$ provided no indications of M1 mutagenicity.

hERG Channel Inhibition Assay-The human Ether-á-go-go-Related Gene (hERG) channel is a voltage-gated potassium channel in cardiac cells that is essential for cardiac repolarization. With the inhibition of this channel, the electrical depolarization and repolarization of the heart ventricles can be extended, leading to potentially fatal cardiac malfunction. Evaluating a novel API's ability to interfere with the hERG channel functions is a standard safety assessment test conducted during drug development. ${ }^{50}$ One way to evaluate the ability of a compound to inhibit the ion channel is via the patch-clamp technique. Here the patch clamp hERG assay was conducted using Chinese Hamster Ovary (CHO) cells expressing the hERG channel (Figure 2). $\mathrm{IC}_{50}$ values below $0.1 \mu \mathrm{M}$ are defined as highly potent inhibitors of the hERG channel, values between $0.1-1 \mu \mathrm{M}$ as potent, values between $1-10 \mu \mathrm{M}$ as moderately potent and finally, $\mathrm{IC}_{50}$ values above $10 \mu \mathrm{M}$ are typically categorized as having little to no inhibition of the channel. ${ }^{51}$

The positive control, quinidine, showed a distinct decrease from an average of $90 \pm 4 \%$ to $1 \pm 6 \%$ in the post-treatment current across the ion channel with increasing concentrations of the compound (Figure 2). A nonlinear regression analysis, using GraphPad Prism 6, was performed to calculate an IC50 value of $1.66 \mu \mathrm{M}$ for quinidine. As a result, quinidine was categorized as a moderately potent inhibitor of the hERG channel. Treatment with M1 up to a concentration of $25 \mu \mathrm{M}$ did not result in significant differences in the observed current since they measured between $93 \pm 3 \%$ to $101 \pm 1 \%$ of the pre-compound current. Consequently, the $\mathrm{IC}_{50}$ value for $\mathrm{M} 1$ is higher than $25 \mu \mathrm{M}$, indicating that $\mathrm{M} 1$ does not inhibit the hERG channel.

\section{In vitro efficacy}

$\mathrm{ABZ}$ is a marketed drug for anti-helminthic treatment. It has low solubility in water and low permeability in the intestine after oral delivery. $\mathrm{M} 1$ increases the solubility of $\mathrm{ABZ}^{36}$ and thus we explored the possibility of M1 formulation of ABZ for systemic delivery via IV dosing. It is important to evaluate the efficacy of ABZ after binding to M1 to ensure that the carrier does not interfere with the bioactivity of the drug. We used the Cell Death ELISA® 
to establish an $\mathrm{EC}_{50}$ value for the $\mathrm{M} 1 \bullet \mathrm{ABZ}$ formulation on the inhibition of tumor cell growth (Figure 3). Once data was collected, staurosporine-treated samples were set at a $100 \%$ apoptosis (data not shown) and all other data sets were normalized to this value. The ovarian cancer cell line, SK-OV-3, incubated with increasing concentrations of M1•ABZ for $24 \mathrm{~h}$ indicated increasing levels of apoptosis as compared to the staurosporine control. An $\mathrm{EC}_{50}$ value of $3.2 \mu \mathrm{M}$ for $\mathrm{M} 1 \bullet \mathrm{ABZ}$ was calculated from a nonlinear regression analysis using GraphPad Prism 6 software. This value achieved with the M1•ABZ formulation is very similar to the $\mathrm{IC}_{50}$ of $3.88 \mu \mathrm{M}$ that was published for the efficacy of $\mathrm{ABZ}$ formulated in ethanol on SK-OV-3 cells. ${ }^{52}$ Consequently, we deduced that M1 does not significantly inhibit ABZ's capacity to reach and bind to $\beta$-tubulin within the cells and that SK-OV-3 cells may serve as xenograft tumor model for the subsequent in vivo efficacy studies.

\section{In vivo Pharmacokinetic Study}

Pharmacokinetic evaluation of M1•ABZ investigated two routes of administration, IP, which allows for repeated dosing of the drug in future in vivo efficacy studies in the mouse model, and IV, which accounts for $100 \%$ bioavailability of ABZ and its metabolites (Figure 4 and table 2). In the mouse model, IP administration is often used it allows for easy chronic dosing of compounds for parenteral delivery. Nevertheless, for each new drug the bioavailability after IP dosing has to be compared to the bioavailability after IV dosing which is defined as $100 \%$ bioavailability. Consequently, before proceeding into in vivo toxicity and efficacy evaluation of M1•ABZ, we performed a pharmacokinetic study. The experiment was conducted using 5 mice per time point and per administration method. At each of the 8 time points $(5,15,30 \mathrm{~min}$ and 2, 4, 8 16, $24 \mathrm{~h}$ ) blood was collected through cardiac puncture. In addition to $\mathrm{ABZ}$, the active intermediate metabolite of $\mathrm{ABZ}$, albendazole sulfoxide (ABZSO) and inactive metabolite, albendazole sulfone $\left(\mathrm{ABZSO}_{2}\right)$ were also measured in the isolated blood plasma using HPLC analysis as described in Material and Methods and shown in Supplementary Figures S1-4.

Both ABZ and ABZSO were detected in the plasma of mice following IP administration indicating that the drug escapes the peritoneal cavity and reaches systemic distribution (Figure $4 a+b$ ). When compared to IV administration, it was found that the drug reaches systemic distribution at slightly reduced concentrations following IP administration. One bolus injection of M1•ABZ ( 681 and $3.2 \mathrm{mg} / \mathrm{kg}$ ) through the IP route revealed a maximum concentration in the plasma $\left(\mathrm{C}_{\max }\right)$ of $2.47 \mu \mathrm{g} / \mathrm{mL}$ for IV administration and $1.56 \mu \mathrm{g} / \mathrm{mL}$ for IP administration both at a $t_{\max }$ of $5 \mathrm{~min}$ (Table 2). The area under the curve (AUC) for $\mathrm{ABZ}$ was 0.81 and $0.63 \mu \mathrm{g} \cdot \mathrm{h} / \mathrm{mL}$ for IV and IP routes respectively. The percent of absolute bioavailability of ABZ was calculated to be $78 \%$ for the IP dosing. Similarly, the data showed a $\mathrm{C}_{\max }$ of $4.34 \mu \mathrm{g} / \mathrm{mL}$ and a $\mathrm{t}_{\max }$ of $30 \mathrm{~min}$ for ABZSO following IV administration. Following IP administration, the data showed a $\mathrm{C}_{\max }$ of $2.62 \mu \mathrm{g} / \mathrm{mL}$ and a $\mathrm{t}_{\max }$ of $15 \mathrm{~min}$ for ABZSO. AUC for both routes of administration were calculated to be 14.30 and 6.15 $\mu \mathrm{g} \cdot \mathrm{h} / \mathrm{mL}$ for IV and IP respectively, indicating an absolute bioavailability of $43 \%$ for the active intermediate metabolite ABZSO. The $\mathrm{C}_{\max }$ for $\mathrm{ABZSO}_{2}$ were found to be 0.50 and $0.41 \mu \mathrm{g} / \mathrm{mL}$ for the IV and IP routes respectively and $\mathrm{t}_{\max }$ was $2 \mathrm{~h}$ for both routes. The AUC for $\mathrm{ABZSO}_{2}$ was calculated to be $2.94 \mu \mathrm{g} \cdot \mathrm{h} / \mathrm{mL}$ for IV and $2.38 \mu \mathrm{g} \cdot \mathrm{h} / \mathrm{mL}$ for IP 
administration. Our data show $78 \%$ and $43 \%$ of absolute bioavailability for ABZ and ABZSO, respectively.

\section{In vivo Maximum Tolerated Dose}

ABZ is a widely used drug with a well-established safety record for oral delivery and treatment of gastrointestinal helminthic infections. In mice, the repeated oral dosing of 30 $40 \mathrm{mg} / \mathrm{kg} / \mathrm{day}$ of the drug for 4-90 days resulted in no significant signs of toxicity. ${ }^{53} \mathrm{In}$ an attempt to formulate $\mathrm{ABZ}$ for parenteral delivery many different excipients have been used to increase its solubility. These new formulations are tested for toxicity as they are developed. Here we attempted to establish a safe dosing schedule for M1 $\bullet$ ABZ prior to commencing with in vivo treatment studies. For this purpose, a maximum tolerated dose (MTD) study was conducted using outbred female Swiss Webster mice separated into the following groups ( $\mathrm{n}=7)$ : untreated (UT), M1 $(681 \mathrm{mg} / \mathrm{kg})$ and M1 $\bullet \mathrm{ABZ}$ at increasing doses of $\operatorname{ABZ}(0.5,1.4,2.3$ and $3.2 \mathrm{mg} / \mathrm{kg}$ ) (Figure 5). Mice were dosed once daily for 14 days through the IP route with $\mathrm{M} 1$ or increasing concentrations of M1•ABZ. Throughout the study, all mice maintained weights well above $80 \%$ of their original starting weight (humane endpoint). No visual signs of sickness or distress were observed during the dosing or the subsequent observation periods. Accordingly, the highest amount of $3.2 \mathrm{mg} / \mathrm{kg}$ of ABZ formulated with $681 \mathrm{mg} / \mathrm{kg} \mathrm{M} 1$ was chosen for future in vivo efficacy studies.

\section{In vivo M1·ABZ Efficacy}

The formulation of $\mathrm{ABZ}$ with $\mathrm{M} 1$ allowed for increased systemic delivery of $\mathrm{ABZ}$ when compared to other formulation methods like $0.5 \% \mathrm{CMC}$. A tumor treatment study using M1 at $681 \mathrm{mg} / \mathrm{kg}$ or the same amount of M1 formulated with $3.2 \mathrm{mg} / \mathrm{kg} \mathrm{ABZ}$ with either a once daily or twice daily dosing was conducted in order to address the therapeutic potential of this novel formulation. Xenograft tumors were established using the SK-OV-3 ovarian cancer cell line in athymic mice.

In the first experiment (Figure 6a-c), treatment started once tumors reached a volume of approximately $300 \mathrm{~mm}^{3}$ at which point they were in a phase of rapid growth. Mice, in all groups, maintained weights well above $80 \%$ of their original starting weight (Figure 6a). Furthermore, no signs of sickness or distress were observed indicating mice maintain good health throughout treatment. This result was impressive considering that high doses of both $\mathrm{M} 1$ and $\mathrm{M} 1 \bullet \mathrm{ABZ}$ were administered once and twice daily for 50 consecutive days. This data not only further supports the safety of M1, but also suggests that M1•ABZ is non-toxic toward healthy cells. This aggressive treatment schedule led to decreased tumor growth rates in the SK-OV-3 xenografts (Figure 6b). The slope of tumor growth rate for the UT group was $49.15 \pm 2.0 \mathrm{~mm} /$ day, for the M1 group $43.3 \pm 2.0 \mathrm{~mm}^{3} /$ day, $\mathrm{ABZ}$ once daily dosing $26.7 \pm 1.5 \mathrm{~mm}^{3} /$ day, and finally $21.3 \pm 1.4 \mathrm{~mm}^{3} /$ day for the $\mathrm{M} 1 \bullet \mathrm{ABZ}$ twice daily dosing. When compared to the UT group, the M1 tumor growth rate was found to be significantly different with a $p$-value of 0.04 . Both once and twice daily $\mathrm{M} 1 \bullet \mathrm{ABZ}$ dosing tumor growth rates were found to be significantly different from the UT growth rate with $p \unlhd 0.0001$. Furthermore, log-rank analysis of the survival curves (Figure 6c) indicated significant differences between once and twice $\mathrm{M} 1 \bullet \mathrm{ABZ}$ daily dosing groups when compared to the UT 
group. The M1 survival curve was found to not be significantly different from that of the UT group.

A second in vivo efficacy study was conducted using only the once daily dosing and treatment began when tumors were at a volume of approximately $100 \mathrm{~mm}^{3}$, before the period of increased growth rate (Figure $6 \mathrm{~d}-\mathrm{f}$ ). Most mice in M1 and M1•ABZ groups maintained weights well above $80 \%$ of their initial starting weight, however, one mouse in the UT group dropped down to $81 \%$ of its starting weight on day 42 but regained weight up to $89 \%$ prior to its euthanization (Figure 6d). This experiment further supported a high safety profile for M1 and M1•ABZ. Tumor volume showed significantly attenuated tumor growth rates for the $\mathrm{M} 1 \bullet \mathrm{ABZ}$ treated group during the 5 week dosing period, however, once dosing concluded, tumors resumed rapid growth (Figure 6e). Nevertheless, the slopes of the rapid tumor growth phases for the UT, M1 and M1•ABZ groups were as follows $42.9 \pm 2.8$, $35.4 \pm 1.9$ and $24.4 \pm 1.1 \mathrm{~mm}^{3} /$ day respectively. Statistical analysis presented with a $p$-value of 0.02 when the M1 slope was compared to the UT group indicating a significant difference between the two tumor growth rates. A likewise comparison between the M1•ABZ and UT groups indicated an extremely significant difference in tumor growth rates $(p<0.0001)$. This suggests that though the tumor growth rate increases after ceasing $\mathrm{M} 1 \bullet \mathrm{ABZ}$ administration, the treatment still results in an attenuated tumor growth when compared to the UT group. Finally, log-rank analysis showed that the M1•ABZ survival curve was significantly different from the UT group while the M1 group was not significantly different from the control group (Figure 6f).

In conclusion, both of our in vivo tumor efficacy studies indicated that $\mathrm{M} 1$ and $\mathrm{M} 1 \bullet \mathrm{ABZ}$ are both non-toxic at high doses and $\mathrm{M} 1 \bullet \mathrm{ABZ}$ is able to extend mouse survival by attenuating the growth rates of SK-OV-3 tumors.

\section{DISCUSSION}

M1 previously demonstrated the ability to solubilize a variety of API. Here we demonstrate that M1•ABZ has a potent antitumor activity and does not present any sign of toxicity. Previous in vitro toxicity assay performed on monocyte, kidney and liver cells showed no cytotoxicity under $10 \mathrm{mM}$ of M1. ${ }^{36}$ Here, the Ames test data demontrated also that M1 does not induce mutagenicity. Although extensive Ames test data on the cyclodextrins alone is not available, several tests conducted with prospective drugs indicated non-mutagenicity. ${ }^{4}$ The results of the hERG assay show that M1 does not inhibit the hERG channel and, therefore, does not seem to present a serious risk of cardiac toxicity in humans. Nevertheless, further testing in vivo using higher concentrations of M1 and an electrocardiogram (ECG) analysis will need to be conducted in order to confirm that M1 does not have inhibitory effects on the cardiac muscle. ${ }^{54}$ Several published data on the cardiac safety of cyclodextrins demonstrated interference with the hERG. ${ }^{55,56}$ In contrast, clinical evaluation of $\gamma-\mathrm{CD}$, marketed as sugammadex, indicated no relevant effects of the compound on QT interval. ${ }^{57}$ The fact that Captisol ${ }^{\circledR}$ is the excipient for several FDAapproved drug formulations that have not resulted in cardiac toxicity in patients speaks for its biosafety. ${ }^{5}$ 
Previous studies explored the formulation of ABZ with different excipients; for example, one study conducted using $5,10,25,40$ and $50 \mathrm{mg} / \mathrm{kg}$ of HP- $\beta$-CD•ABZ demonstrated no toxicity. However, following on bolus IP injection of $60 \mathrm{mg} / \mathrm{kg}$ of HP- $\beta-\mathrm{CD} \bullet A B Z$ resulted in immobility and subsequent euthanization within $2 \mathrm{~h}$ of dosing. ${ }^{58}$ This toxicity was primarily attributed to the excipient, which consisted of a combination of HP- $\beta-C D$ and glacial acetic acid. $\mathrm{CDs}$ alone, in a neutral $\mathrm{pH}$, cannot efficiently increase $\mathrm{ABZ}$ solubility and, as a result, additional excipients like acetic acid must be used in combination to lower the $\mathrm{pH}$ and increase CD-mediated solubilization of ABZ. In this instance, a dosing HP- $\beta$ $\mathrm{CD} \bullet \mathrm{ABZ}$ that contained more than $0.5 \mathrm{~mL} / \mathrm{kg}$ of glacial acetic acid resulted in severe toxicity, in turn, limiting the maximum drug dose deliverable to $50 \mathrm{mg} / \mathrm{kg}$. Other common solubilizing agents used to formulate $\mathrm{ABZ}$ are $0.5 \%$ hydroxypropyl methyl cellulose (HPMC) and $0.5 \%$ carboxymethyl cellulose (CMC). Both excipients can increase ABZ solubility to $150 \mathrm{mg} / \mathrm{kg}$ with little signs of toxicity following IP administration. However, these formulations have resulted in low systemic distribution due to limited absorption following oral and IP administration, suggesting they would be ineffective unless used for localized treatment of intestinal or cancer of peritoneal cavity resident organs. ${ }^{45,53,59,60}$

Administration routes and pharmacokinetics properties influence directly the efficiency of the injected drug. Our data demonstrate that IP administration significantly reduces the amount of available active drug ABZSO when compared to IV dosing but it also shows that $\mathrm{ABZ}$ and $\mathrm{ABZSO}$ can have access to systemic distribution after injection of $\mathrm{M} 1 \bullet \mathrm{ABZ}$ into the peritoneal cavity. Consequently, IP administration will underestimate the therapeutic potential of M1•ABZ for future IV delivery in humans. Various pharmacokinetic studies evaluating ABZ plasma concentrations following IP and oral administration have been conducted. ${ }^{45,58,61}$ One such investigation evaluated mouse plasma concentrations following IP administration of $50 \mathrm{mg} / \mathrm{kg}$ of ABZ solubilized in hydroxypropyl- $\beta$-CD (HP- $\beta-\mathrm{CD}$ ) or $0.5 \%$ hydroxypropyl methyl cellulose (HPMC). ${ }^{60} \mathrm{HPMC} \bullet \mathrm{ABZ}$ administration resulted in an AUC of $8.1 \mu \mathrm{g} \cdot \mathrm{h} / \mathrm{mL}$ for $\mathrm{ABZ}$ and $14.4 \mu \mathrm{g} \cdot \mathrm{h} / \mathrm{mL}$ for ABZSO. In contrast, administration with HP- $\beta$-CD •ABZ showed significantly higher values of AUC $(18.7$ and $105.7 \mu \mathrm{g} \cdot \mathrm{h} / \mathrm{mL})$ indicating improved pharmacokinetics. ${ }^{60}$ The formulation of ABZ in HP- $\beta-C D$ and HPMC achieved higher total amounts of $\mathrm{ABZ}$ and ABZSO delivered into the plasma compared to M1•ABZ delivery. Nevertheless, this study did not compare the IP delivery to IV in order to assess the percent of absolute bioavailability achieved. This value would allow direct comparison of the relative efficacy of the delivery methods because we only dosed 3.2 $\mathrm{mg} / \mathrm{kg} \mathrm{ABZ}$ that is about 15 times less then in the described study. Overall, the pharmacokinetics analysis demonstrates that $\mathrm{ABZ}$ and the active intermediate metabolite ABZSO can be systemically delivered via IP administration of M1•ABZ complex. Work done with $\mathrm{HP}-\beta-\mathrm{CD} \bullet \mathrm{ABZ}$ and $\mathrm{HPMC} \bullet \mathrm{ABZ}$ formulations showed moderate increases to survival with just one IP dosing. Further studies with these systems seemed to be limited due to high toxicity as mentioned previously. ${ }^{60}$ The suppression of malignant ascites was observed when mice bearing OVCAR-3 (human ovarian adenocarcinoma) received 150 $\mathrm{mg} / \mathrm{kg}$ of ABZ 3 times a week for 4 weeks through IP. It should be noted, however, that this study, like many other ABZ efficacy studies, utilized a xenograft model established in the peritoneal cavity making it a localized, intratumoral administration system. ${ }^{60-62}$ In contrast, one study showed moderate improvements in mouse survival when daily oral doses (50 and 
$150 \mathrm{mg} / \mathrm{kg}$ ) of ABZ tablets mixed with $50 \%$ sesame oil were used to treat glioblastoma multiforme, an aggressive form of brain cancer. ${ }^{63}$ A second study conducted using SKHEP-1 (human liver adenocarcinoma) xenografts located on the flank of mice required a daily oral dose of $300 \mathrm{mg} / \mathrm{kg}$ of ABZ in sesame oil to see an antitumor effect. ${ }^{64}$ The necessity for these high doses of $\mathrm{ABZ}$ has been attributed to rapid metabolism, low absorption and inaccessibility to the tumor. However, in the case of M1•ABZ (Figure 6), promising results with a low daily dose of $3.2 \mathrm{mg} / \mathrm{kg}$ of $\mathrm{ABZ}$ suggests that $\mathrm{M} 1 \bullet \mathrm{ABZ}$ is likely more efficiently absorbed through the peritoneal cavity into systemic circulation and reaches the tumor at a higher dose than the previous studies mentioned above.

The current proof-of-concept study represents the first in vivo evaluation of M1 as a new solubilizing excipient for insoluble drugs. The ability of M1 to solubilize a wide range of drugs, its low toxicity, and the in vivo efficacy of M1•ABZ suggests that M1 may become an important addition to the current toolbox of solubilizing excipients available to the pharmaceutical industry.

\section{Supplementary Material}

Refer to Web version on PubMed Central for supplementary material.

\section{Acknowledgments}

The work was supported by a grant from the NIH/NCI (R01 CA168365) B.Z. thanks the University of Maryland for a Wylie Dissertation Fellowship.

\section{REFERENCES}

1. Williams HD, Trevaskis NL, Charman SA, Shanker RM, Charman WN, Pouton CW, Porter CJH. Strategies to address low drug solubility in discovery and development. Pharmacol. Rev. 2013; 65:315-499. [PubMed: 23383426]

2. Savjani KT, Gajjar AK, Savjani JK. Drug Solubility: Importance and Enhancement Techniques. ISRN Pharmaceutics. 2012; 2012:1-10.

3. Barenholz Y. Doxil®--the first FDA-approved nano-drug: lessons learned. J Control Release. 2012; 160:117-134. [PubMed: 22484195]

4. Stella VJ, He Q. Cyclodextrins. Toxicologic Pathology. 2008; 36:30-42. [PubMed: 18337219]

5. Ligand Pharmaceuticals, Inc. Captisol ${ }^{\circledR}+$ Partnerships \& Collaborations, Url. (n.d.), http:// www.captisol.com/partnerships-collaborations/.

6. Lee JW, Samal S, Selvapalam N, Kim H-J, Kim K. Cucurbituril Homologues and Derivatives: New Opportunities in Supramolecular Chemistry, Acc. Chem. Res. 2003; 36:621-630.

7. Lagona J, Mukhopadhyay P, Chakrabarti S, Isaacs L. The cucurbit[n]uril family. Angew. Chem. Int. Ed. Engl. 2005; 44:4844-4870. [PubMed: 16052668]

8. Macartney DH. Encapsulation of Drug Molecules by Cucurbiturils: Effects on their Chemical Properties in Aqueous Solution. Isr. J. Chem. 2011; 51:600-615.

9. Masson E, Ling X, Joseph R, Kyeremeh-Mensah L, Lu X. Cucurbituril Chemistry: A Tale of Supramolecular Success. RSC Adv. 2012; 2:1213-1247.

10. Nau WM, Florea M, Assaf KI. Deep Inside Cucurbiturils: Physical Properties and Volumes of their Inner Cavity Determine the Hydrophobic Driving Force for Host-Guest Complexation. Isr. J. Chem. 2011; 51:559-577.

11. Walker S, Oun R, McInnes FJ, Wheate NJ. The Potential of Cucurbit[n]urils in Drug Delivery. Isr. J. Chem. 2011; 51:616-624. 
12. Cao L, Śekutor M, Zavalij PY, Mlinarić-Majerski K, Glaser R, Isaacs L. Cucurbit[7]uril. Guest Pair with an Attomolar Dissociation Constant. Angew. Chem. Int. Ed. Engl. 2014; 53:988-993. [PubMed: 24382654]

13. Liu S, Ruspic C, Mukhopadhyay P, Chakrabarti S, Zavalij PY, Isaacs L. The Cucurbit[n]uril Family: Prime Components for Self-Sorting Systems. J. Am. Chem. Soc. 2005; 127:15959-15967. [PubMed: 16277540]

14. Mock WL, Shih NY. Structure and selectivity in host-guest complexes of cucurbituril. J. Org. Chem. 1986; 51:4440-4446.

15. Rekharsky MV, Mori T, Yang C, Ko YH, Selvapalam N, Kim H, Sobransingh D, Kaifer AE, Liu S, Isaacs L, Chen W, Moghaddam S, Gilson MK, Kim K, Inoue Y. A synthetic host-guest system achieves avidin-biotin affinity by overcoming enthalpy-entropy compensation. Proc. Natl. Acad. Sci. U.S.a. 2007; 104:20737-20742. [PubMed: 18093926]

16. Biedermann F, Uzunova VD, Scherman OA, Nau WM, De Simone A. Release of high-energy water as an essential driving force for the high-affinity binding of cucurbit[n]urils. J. Am. Chem. Soc. 2012; 134:15318-15323. [PubMed: 22881280]

17. Hettiarachchi G, Nguyen D, Wu J, Lucas D, Ma D, Isaacs L, Briken V. Toxicology and drug delivery by cucurbit[n] uril type molecular containers. PLoS ONE. 2010; 5:e10514. [PubMed: 20463906]

18. Plumb JA, Venugopal B, Oun R, Gomez-Roman N, Kawazoe Y, Venkataramanan NS, Wheate NJ. Cucurbit[7]uril encapsulated cisplatin overcomes cisplatin resistance via a pharmacokinetic effect. Metallomics. 2012; 4:561-567. [PubMed: 22610518]

19. Uzunova VD, Cullinane C, Brix K, Nau WM, Day AI. Toxicity of cucurbit[7]uril and cucurbit[8]uril: an exploratory in vitro and in vivo study. Org. Biomol. Chem. 2010; 8:2037-2042. [PubMed: 20401379]

20. Walker S, Kaur R, McInnes FJ, Wheate NJ. Synthesis, Processing and Solid State Excipient Interactions of Cucurbit[6]uril and Its Formulation into Tablets for Oral Drug Delivery. Mol. Pharmaceutics. 2010; 7:2166-2172.

21. Dong N, Xue SF, Zhu QJ, Tao Z, Zhao Y, Yang LX. Cucurbit[n]urils $(n=7,8)$ binding of camptothecin and the effects on solubility and reactivity of the anticancer drug. Supramol. Chem. 2008; 20:659-665.

22. Dong N, Wang X, Pan J, Tao Z. Influence of Cucurbit(n=7,8_uril on the Solubility and Stability of Chlorambucil. Acta Chim. Sinica. 2011; 69:1431-1437.

23. Zhao Y, Buck DP, Morris DL, Pourgholami MH, Day AI, Collins JG. Solubilisation and cytotoxicity of albendazole encapsulated in cucurbit[n]uril. Org. Biomol. Chem. 2008; 6:4509. [PubMed: 19039358]

24. Koner ALKL, Ghosh I, Saleh N, Nau WMNM. Supramolecular encapsulation of benzimidazolederived drugs by cucurbit[7]uril. Canadian Journal of Chemistry. 2011; 89:139-147.

25. Jeon YJ, Kim S-Y, Ko YH, Sakamoto S, Yamaguchi K, Kim K. Novel molecular drug carrier: encapsulation of oxaliplatin in cucurbit[7]uril and its effects on stability and reactivity of the drug. Org. Biomol. Chem. 2005; 3:2122-2125. [PubMed: 15917899]

26. McInnes FJ, Anthony NG, Kennedy AR, Wheate NJ. Solid state stabilisation of the orally delivered drugs atenolol, glibenclamide, memantine and paracetamol through their complexation with cucurbit[7]uril. Org. Biomol. Chem. 2010; 8:765-773. [PubMed: 20135032]

27. Miskolczy Z, Megyesi M, Tárkányi G, Mizsei R, Biczók L. Inclusion complex formation of sanguinarine alkaloid with cucurbit[7]uril : inhibition of nucleophilic attack and photooxidation. Org. Biomol. Chem. 2011; 9:1061-1070. [PubMed: 21152661]

28. Saleh N, Koner AL, Nau WM. Activation and Stabilization of Drugs by Supramolecular pKa Shifts: Drug-Delivery Applications Tailored for Cucurbiturils. Angewandte Chemie. 2008; 120:5478-5481.

29. Jung H, Park KM, Yang J-A, Oh EJ, Lee D-W, Park K, Ryu SH, Hahn SK, Kim K. Theranostic systems assembled in situ on demand by host-guest chemistry. Biomaterials. 2011; 32:7687-7694. [PubMed: 21788071] 
30. Kim E, Kim D, Jung H, Lee J, Paul S, Selvapalam N, Yang Y, Lim N, Park K, Kim CG. Facile, Template-Free Synthesis of Stimuli-Responsive Polymer Nanocapsules for Targeted Drug Delivery. Angewandte Chemie. 2010; 122:4507-4510.

31. Loh XJ, del Barrio J, Toh PPC, Lee T-C, Jiao D, Rauwald U, Appel EA, Scherman OA. Triply Triggered Doxorubicin Release From Supramolecular Nanocontainers. Biomacromolecules. 2011; 13:84-91. [PubMed: 22148638]

32. Park KM, Suh K, Jung H, Lee D-W, Ahn Y, Kim J, Baek K, Kim K. Cucurbituril -based nanoparticles : a new efficient vehicle for targeted intracellular delivery of hydrophobic drugs. Chemical Communications. 2009; 0:71-73. [PubMed: 19082002]

33. Cao L, Hettiarachchi G, Briken V, Isaacs L. Cucurbit[7]uril Containers for Targeted Delivery of Oxaliplatin to Cancer Cells. Angew. Chem. Int. Ed. Engl. 2013; 52:12033-12037. [PubMed: 24039074]

34. MA WJ, Chen JM, Jiang L, Yao J, Lu TB. The Delivery of Triamterene by Cucurbit[7]uril: Synthesis, Structures and Pharmacokinetics Study. Mol Pharm. 2013; 10:4698-4705. [PubMed: 24188081]

35. Lee JW, Samal S, Selvapalam N, Kim HJ, Kim K. Cucurbituril homologues and derivatives: new opportunities in supramolecular chemistry. Acc Chem Res. 2003; 36:621-630. [PubMed: 12924959]

36. Ma D, Hettiarachchi G, Nguyen D, Zhang B, Wittenberg JB, Zavalij PY, Briken V, Isaacs L. Acyclic cucurbit[n]uril molecular containers enhance the solubility and bioactivity of poorly soluble pharmaceuticals. Nat Chem. 2012; 4:503-510. [PubMed: 22614387]

37. Zhang B, Isaacs L. Acyclic cucurbit[n] uril-type molecular containers: influence of aromatic walls on their function as solubilizing excipients for insoluble drugs. J. Med. Chem. 2014; 57:95549563. [PubMed: 25369565]

38. Zhang B, Zavalij PY, Isaacs L. Acyclic CB[n]-type molecular containers: effect of solubilizing group on their function as solubilizing excipients. Org. Biomol. Chem. 2014; 12:2413-2422. [PubMed: 24595500]

39. Gilberg L, Zhang B, Zavalij PY, Sindelar V, Isaacs L. Acyclic cucurbit[n]uril-type molecular containers: influence of glycoluril oligomer length on their function as solubilizing agents. Org. Biomol. Chem. 2015; 13:4041-4050. [PubMed: 25731639]

40. Bernard, WS.; Christopher, PW. International Agency for Research on Cancer. World Health Organization; 2014. World Cancer Report 2014.

41. Lacey E. Mode of action of benzimidazoles. Parasitol. Today (Regul. Ed.). 1990; 6:112-115. [PubMed: 15463312]

42. Barrowman MM, Marriner SE, Bogan JA. The binding and subsequent inhibition of tubulin polymerization in Ascaris suum (in vitro) by benzimidazole anthelmintics. Biochemical Pharmacology. 1984; 33:3037-3040. [PubMed: 6487354]

43. Morris DL, Jourdan JL, Pourgholami MH. Pilot study of albendazole in patients with advanced malignancy. Effect on serum tumor markers/high incidence of neutropenia. Oncology. 2001; 61:42-46. [PubMed: 11474247]

44. Pourgholami MH, Szwajcer M, Chin M, Liauw W, Seef J, Galettis P, Morris DL, Links M. Phase I clinical trial to determine maximum tolerated dose of oral albendazole in patients with advanced cancer. 2010; 65:597-605.

45. Marriner SE, Morris DL, Dickson B, Bogan JA. Pharmacokinetics of albendazole in man. Eur. J. Clin. Pharmacol. 1986; 30:705-708. [PubMed: 3770064]

46. Connors, KA. Binding Constants. New York: John Wiley and Sons; 1987. p. 261-281.

47. Higuchi T, Connors KA. Phase-Solubility Techniques. Adv. Anal. Chem. Instrum. 1965; 4:117212.

48. Hoffmann U, Grosse-Sundrup M, Eikermann-Haerter K, Zaremba S, Ayata C, Zhang B, Ma D, Isaacs L, Eikermann M. Calabadion: A new agent to reverse the effects of benzylisoquinoline and steroidal neuromuscular-blocking agents. Anesthesiology. 2013; 119:317-325. [PubMed: 23549405]

49. Mortelmans K, Zeiger E. The Ames Salmonella/microsome mutagenicity assay. Mutat. Res. 2000; 455:29-60. [PubMed: 11113466] 
50. Gintant GA, Su Z, Martin RL, Cox BF. Utility of hERG assays as surrogate markers of delayed cardiac repolarization and QT safety. Toxicologic Pathology. 2006; 34:81-90. [PubMed: 16507548]

51. Roche O, Trube G, Zuegge J, Pflimlin P, Alanine A, Schneider G. A virtual screening method for prediction of the HERG potassium channel liability of compound libraries. Chembiochem. 2002; 3:455-459. [PubMed: 12007180]

52. Pourgholami MH, Wangoo KT, Morris DL. Albendazole-Cyclodextrin Complex: Enhanced Cytotoxicity in Ovarian Cancer Cells. Anticancer Res. 2008; 28:2775-2779. [PubMed: 19035309]

53. Pourgholami MH, Cai ZY, CHU SWL, Galettis P, Morris DL. The Influence of Ovarian Cancer Induced Peritoneal Carcinomatosis on the Pharmacokinetics of Albendazole in Nude Mice. Anticancer Res. 2010; 30:423-428. [PubMed: 20332449]

54. Food and Drug Administration. HHS, International Conference on Harmonisation; guidance on S7A safety pharmacology studies for human pharmaceuticals; availability. Notice. Fed Regist. 2001; 66:36791-36792. [PubMed: 12356097]

55. Carr DB, McDonnell Moorehead T, Bouchard A, Sprenger CR, Hamilton DA, Lang E, Madden D, Lacouture PG, Wright IVC. Effects of injectable HP $\beta C D$-diclofenac on the human delayed rectifier potassium channel current in vitro and on proarrhythmic QTc in vivo. Clin Ther. 2013; 35:646-658. [PubMed: 23578606]

56. Mikhail, A.;. Fischer C, Patel A, Long MA, Limberis JT, Martin RL, Cox BF, Gintant GA, Su Z. Hydroxypropyl beta-cyclodextrins: a misleading vehicle for the in vitro hERG current assay. J. Cardiovasc. Pharmacol. 2007; 49:269-274. [PubMed: 17513944]

57. de Kam P-J, van Kuijk J, Smeets J, Thomsen T, Peeters P. Sugammadex is not associated with QT/QTc prolongation: methodology aspects of an intravenous moxifloxacin-controlled thorough QT study. Int J Clin Pharmacol Ther. 2012; 50:595-604. [PubMed: 22735462]

58. Ehteda A, Galettis P, CHU SWL, Pillai K, Morris DL. Complexation of Albendazole with Hydroxypropyl- $\beta$-Cyclodextrin Significantly Improves its Pharmacokinetic Profile, Cell Cytotoxicity and Antitumor Efficacy in Nude Mice. Anticancer Res. 2012; 32:3659-3666. [PubMed: 22993303]

59. Cai Z-Y, Galettis P, Lu Y, Morris DL, Pourgholami MH. Pharmacokinetics of albendazole in New Zealand white rabbits: Oral versus intraperitoneal administration. Anticancer Res. 2007; 27:417422. [PubMed: 17352262]

60. Hossein Pourgholami M. Albendazole: a Potent Inhibitor of Vascular Endothelial Growth Factor and Malignant Ascites Formation in OVCAR-3 Tumor-Bearing Nude Mice. Clinical Cancer Research. 2006; 12:1928-1935. [PubMed: 16551879]

61. Dayan AD. Albendazole, mebendazole and praziquantel. Review of non-clinical toxicity and pharmacokinetics. Acta Tropica. 2003; 86:141-159. [PubMed: 12745134]

62. Pourgholami MH, Akhter J, Wang L, Lu Y, Morris DL. Antitumor activity of albendazole against the human colorectal cancer cell line HT-29: in vitro and in a xenograft model of peritoneal carcinomatosis. Cancer Chemother. Pharmacol. 2005; 55:425-432. [PubMed: 15565325]

63. Bai R-Y, Staedtke V, Aprhys CM, Gallia GL, Riggins GJ. Antiparasitic mebendazole shows survival benefit in 2 preclinical models of glioblastoma multiforme. Neuro-Oncology. 2011; 13:974-982. [PubMed: 21764822]

64. Pourgholami MH, Woon L, Almajd R, Akhter J, Bowery P, Morris DL. In vitro and in vivo suppression of growth of hepatocellular carcinoma cells by albendazole. Cancer Letters. 2001; 165:43-49. [PubMed: 11248417] 

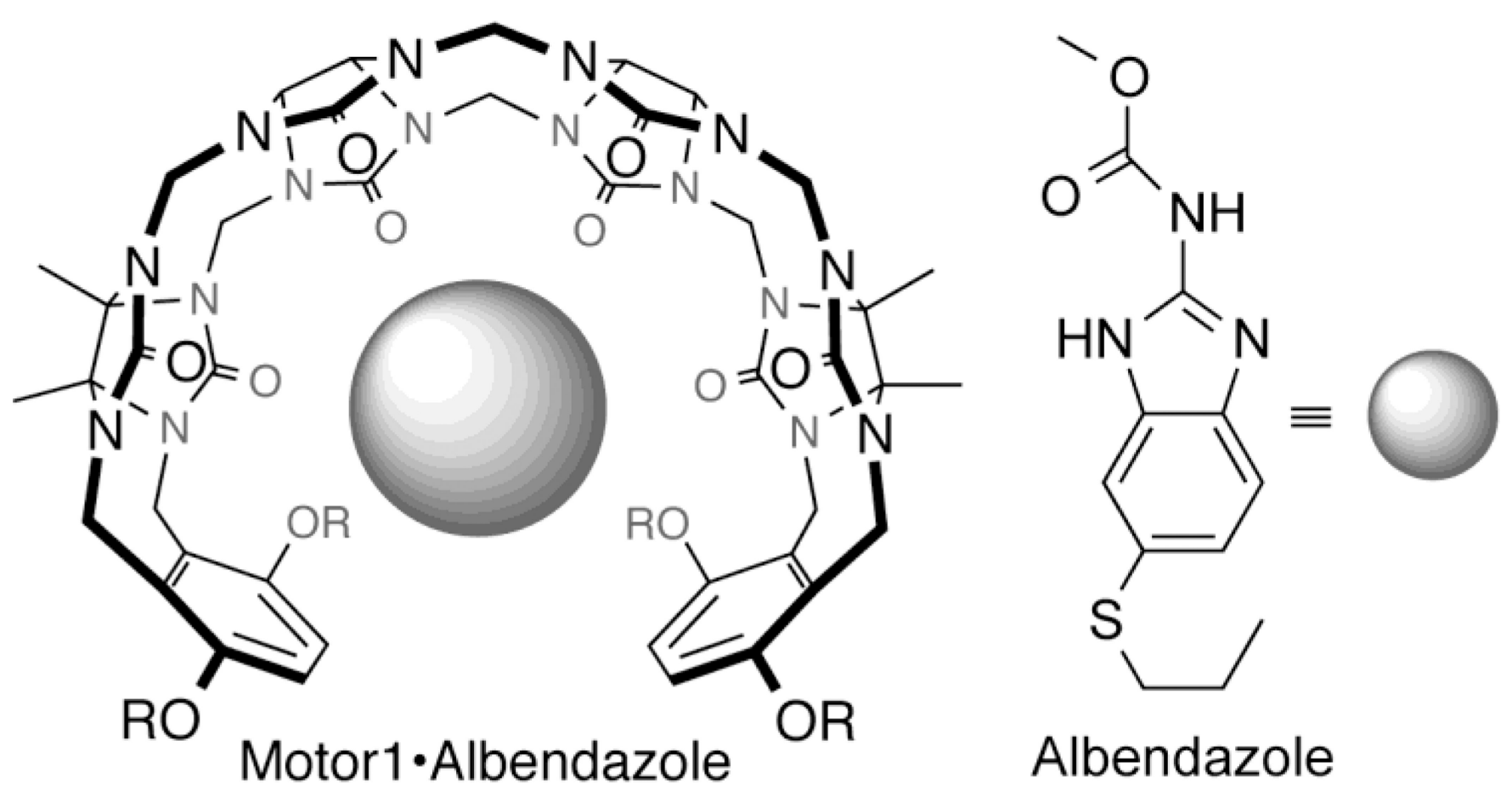

Albendazole

Figure 1.

Structures of drug and excipient. Motor $1\left(\mathrm{M} 1, \mathrm{R}=\left(\mathrm{CH}_{2}\right)_{3} \mathrm{SO}_{3} \mathrm{Na}\right)$ is an acyclic cucurbit[n]uril-type compound that is highly soluble in aqueous solution $(105 \mathrm{mM})$ and its flexible structure and unique binding properties make it an excellent solubilizing excipient. Albendazole (ABZ) is a very poorly soluble anti-helminthic drug that is currently being repurposed as an anticancer agent due to its ability to target the microtubules of dividing cells. 


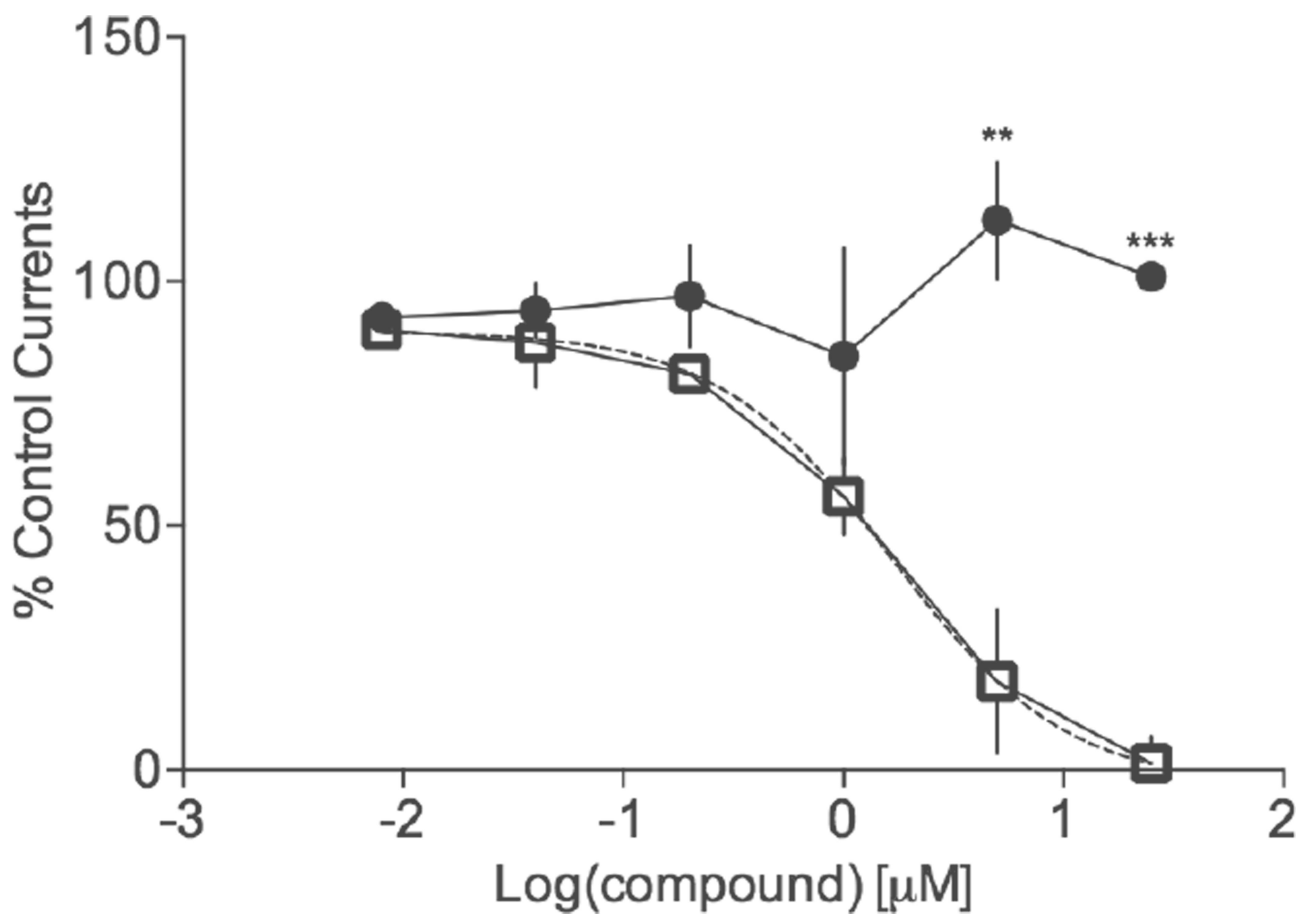

Figure 2.

M1 does not inhibit the hERG channel. The hERG assay was conducted using transfected Chinese Hamster Ovary (CHO)-hERG cells in an automated patch clamp study. Quinidine (closed squares) was used as a positive control. GraphPad Prism 6 was used to generate the best-fit, nonlinear line of regression (dotted line) to calculate its IC50 of $1.66 \mu \mathrm{M}$. The IC50 of M1 (closed circles) was higher than $25 \mu \mathrm{M}$. Values are an average of at least three replicates with corresponding standard deviation values $(* p=0.01-0.05 ; * * p=0.001-0.01$; $* * * p<0.0001)$. 


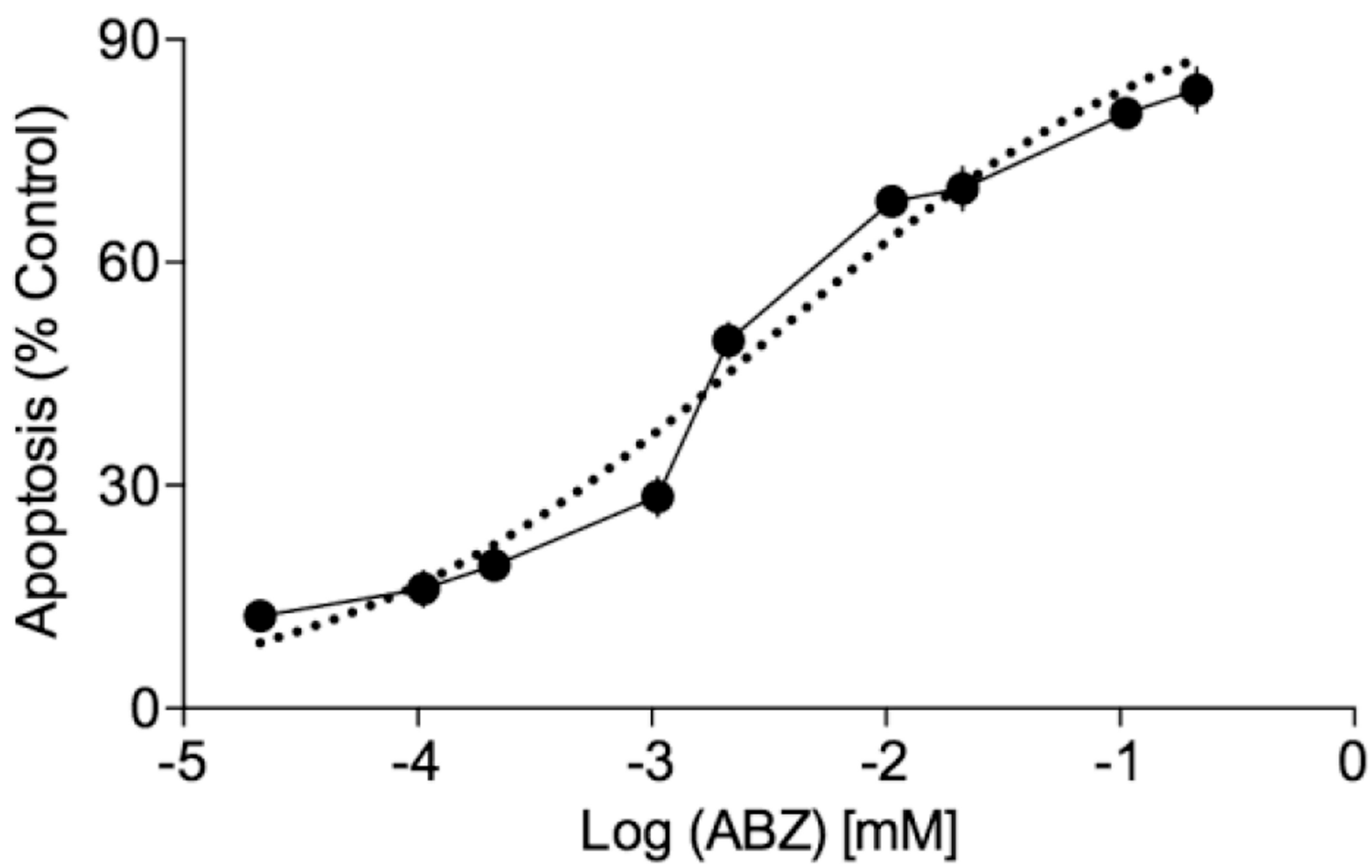

Figure 3.

The ovarian cancer cell line, SK-OV-3, is susceptible to M1 $\bullet A B Z$ treatment. SK-OV-3 cells were seeded at $5 \times 10^{5}$ cells/well overnight followed by $24 \mathrm{~h}$ treatment with increasing concentrations of M1•ABZ. The Roche Cell Death ELISA ${ }^{\circledR}$ was performed to quantify apoptotic cell death. Staurosporine $(1 \mu \mathrm{M})$ was used as a positive control and the average of this control was set at a $100 \%$ apoptosis. The average $(n=6)$ and standard deviation is shown. GraphPad Prism 6 was used to generate the best-fit line of regression (dotted line) to calculate the $\mathrm{EC}_{50}$ value of $3.2 \mu \mathrm{M}$ for ABZ efficacy. 

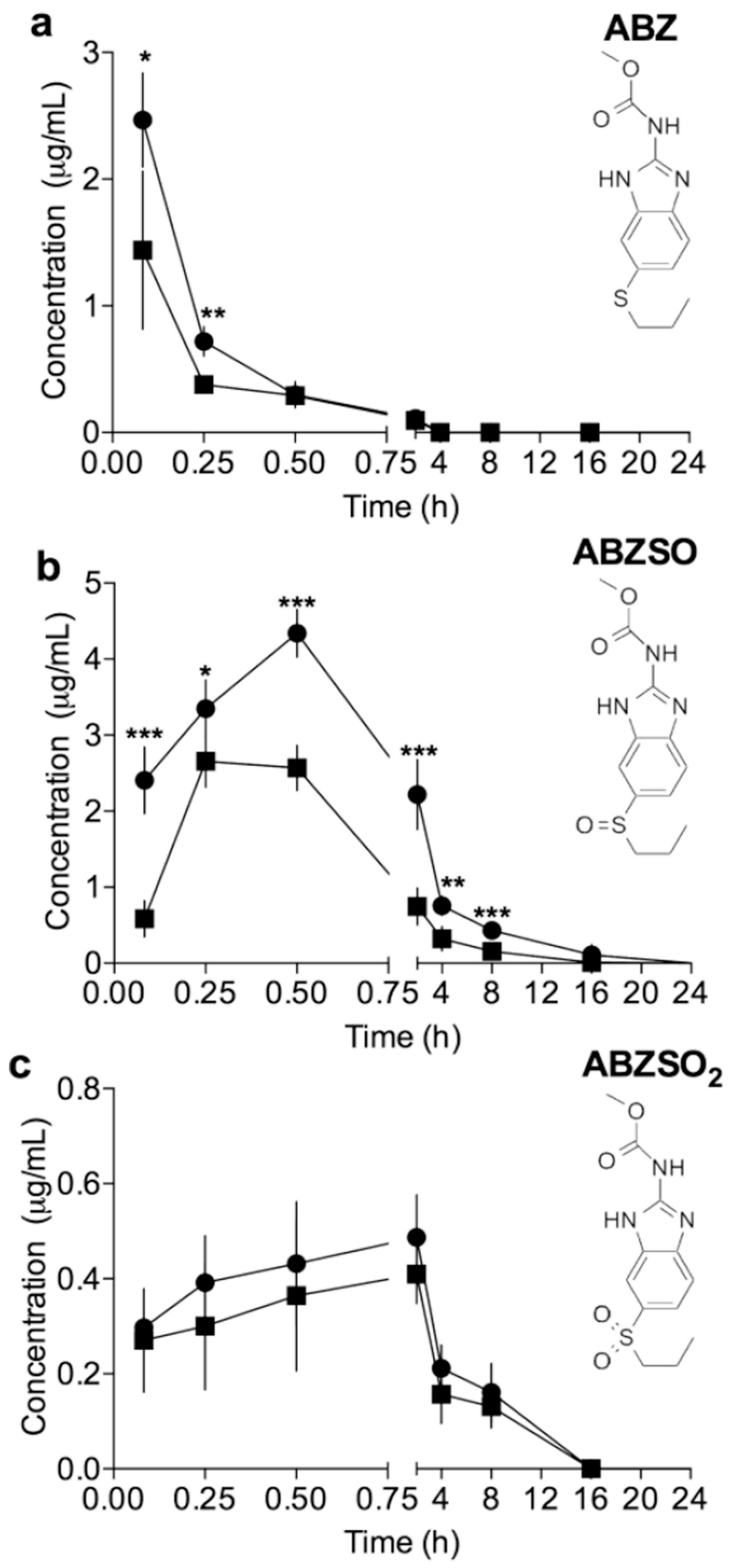

Figure 4.

Pharmacokinetic evaluation following IV and IP administration of M1•ABZ indicated that the drug escapes the peritoneal cavity and reaches systemic circulation. Swiss Webster mice were randomly separated into groups of 5 and administered M1 $\bullet A B Z$ intravenously. Blood was collected and plasma isolated from each mouse at indicated time points. Concentrations of $\mathrm{ABZ}(\mathbf{a}), \mathrm{ABZSO}(\mathbf{b})$ and $\mathrm{ABZSO}_{2}(\mathbf{c})$ were determined by an HPLC assay and values following IP administration (closed squares) or IV dosing (closed circles) are shown. The 
average $(\mathrm{n}=5)$ and standard deviation is shown. GraphPad Prism 6 was used to conduct the student $t$-test $(* p=0.01-0.05 ; * * p=0.001-0.01 ; * * * p<0.0001)$. 


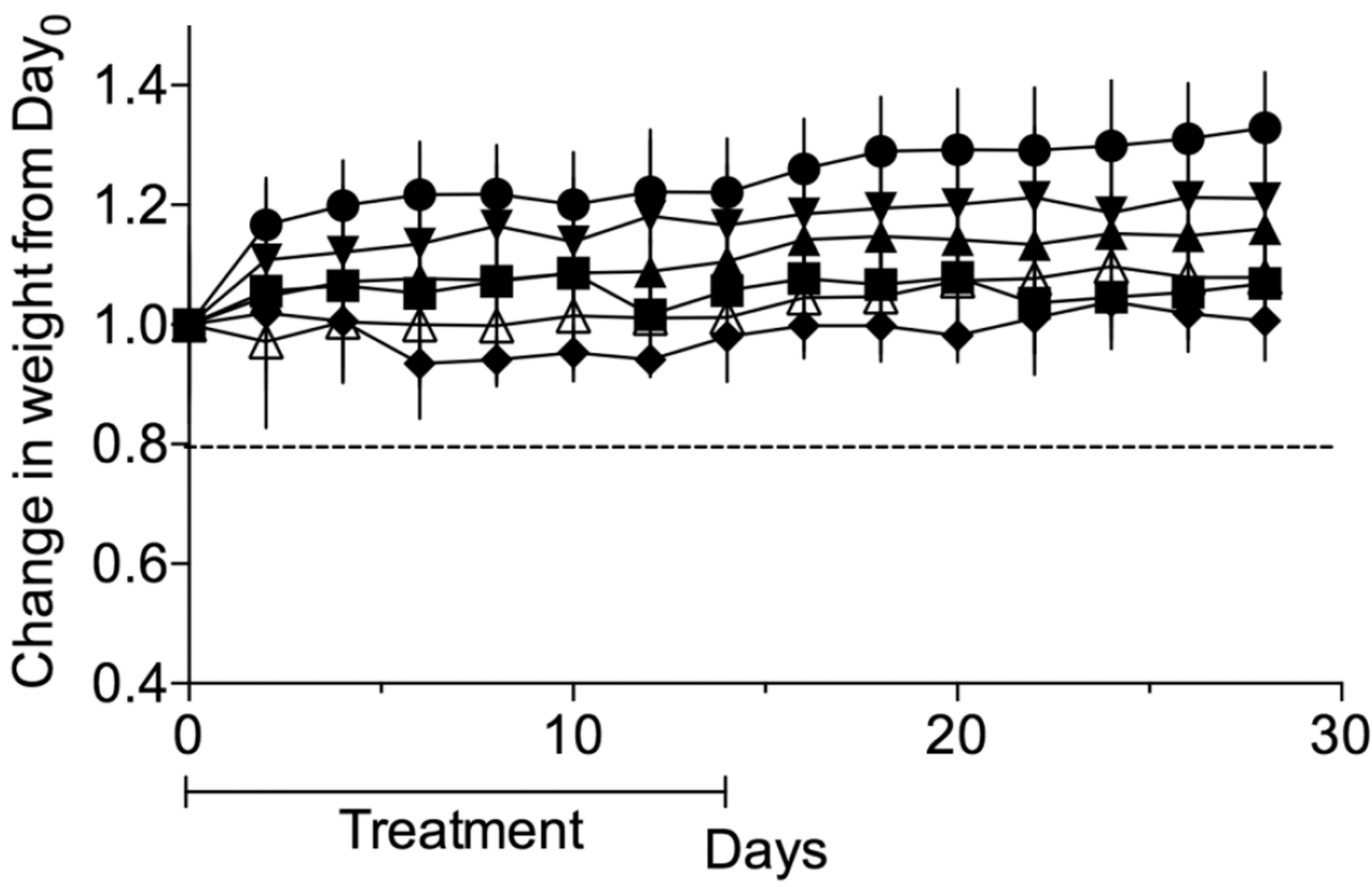

Figure 5.

Daily dosing of mice with M1 (681 mg/kg) or ABZ (up to $3.2 \mathrm{mg} / \mathrm{kg}$ ) for 14 days did not result in significant weight loss. Seven female Swiss Webster mice per group were injected by weight, once daily through IP route with $681 \mathrm{mg} / \mathrm{kg}$ of M1 (closed circle) or $0.5 \mathrm{mg} / \mathrm{kg}$ (closed upward triangle), $1.4 \mathrm{mg} / \mathrm{kg}$ (closed downward triangle), $2.3 \mathrm{mg} / \mathrm{kg}$ (closed diamond) and $3.2 \mathrm{mg} / \mathrm{kg}$ (open upward triangle) of ABZ formulated with M1. An untreated group (closed squares) was also included. Twenty percent weight loss (solid line) indicates humane endpoint. The average and standard deviation of mouse weight per experimental group $(\mathrm{n}=7)$ is plotted. 
a

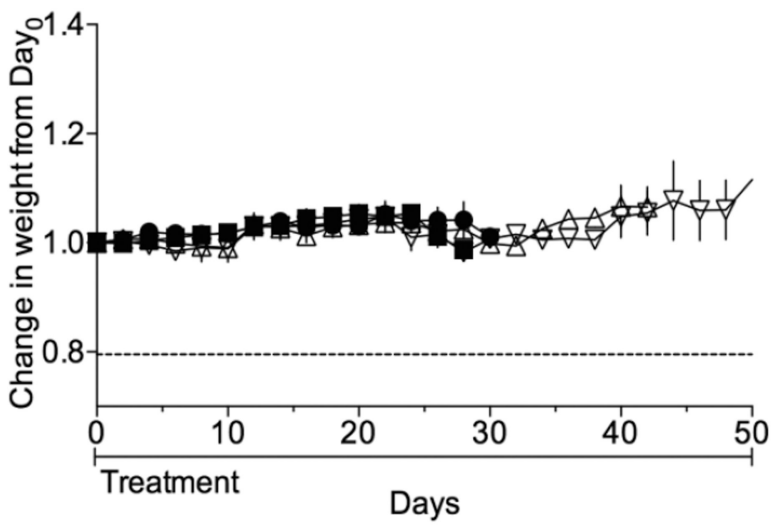

b

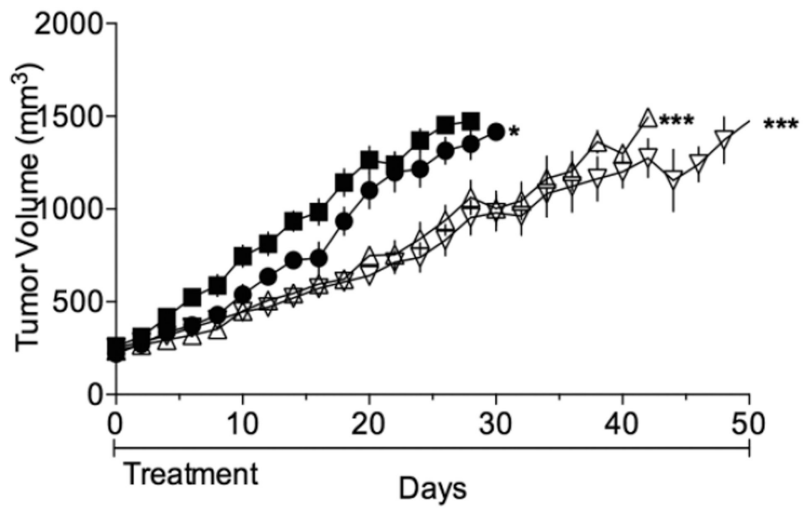

C

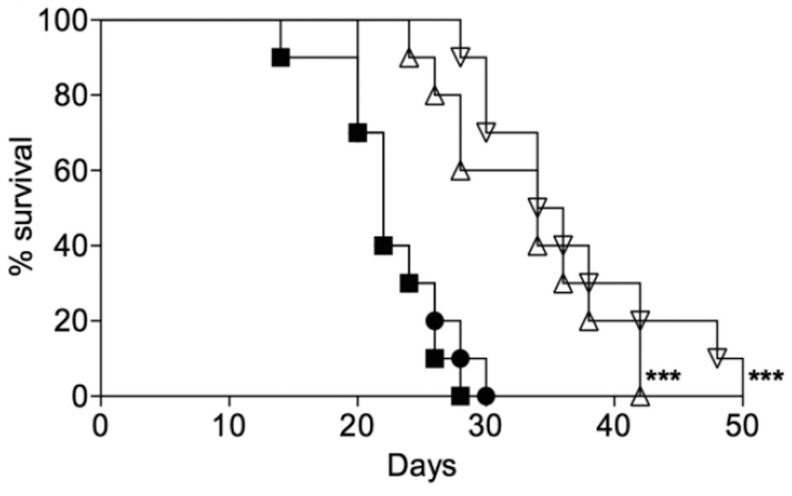

d

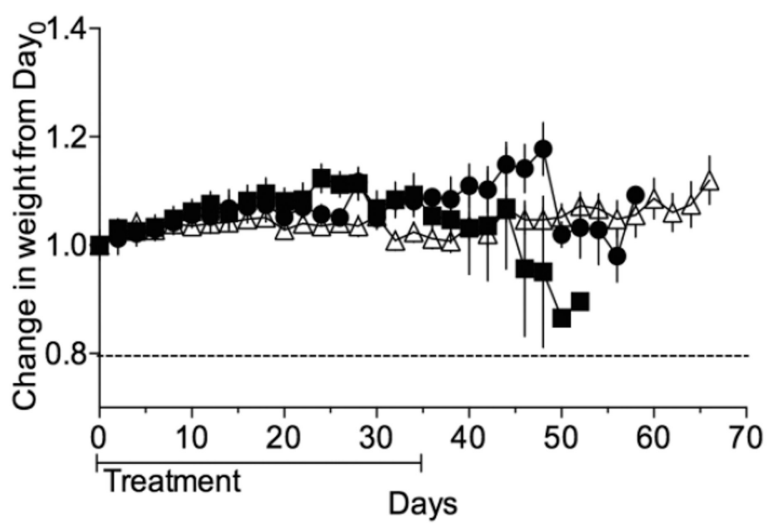

e

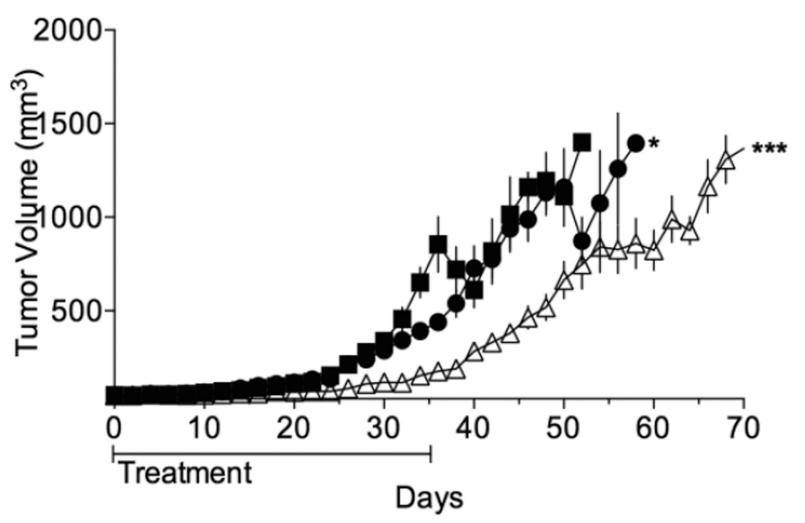

f

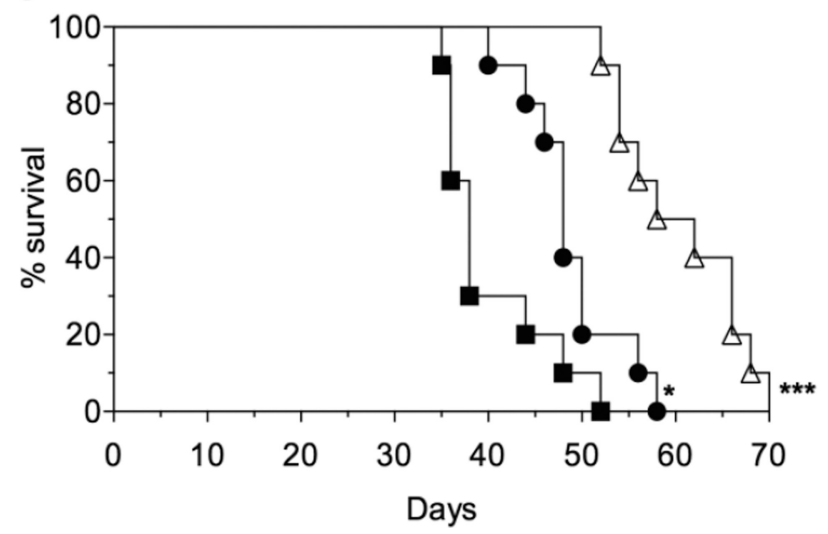

Figure 6.

M1 ABZ treatment attenuates growth rate of SK-OV-3 tumors. Female, athymic mice with SK-OV-3 xenograft tumors maintained healthy weight (a,d), attenuated tumor growth rates $(\mathbf{b}, \mathbf{e})$ and increased survival $(\mathbf{c}, \mathbf{f})$ with once and twice daily dosing of M1•ABZ. (a-c) Mice $(\mathrm{n}=10)$ were dosed either once or twice daily with M1•ABZ $(3.2 \mathrm{mg} / \mathrm{kg})$ through the IP route. Treatment commenced when tumors were approximately $300 \mathrm{~mm}^{3}$, during the rapid tumor growth phase. $(\mathbf{d}-\mathbf{f})$ Mice $(\mathrm{n}=10)$ were dosed once daily with M1•ABZ $(3.2 \mathrm{mg} / \mathrm{kg})$. Treatment commenced when tumors were approximately $100 \mathrm{~mm}^{3}$, prior to the rapid growth 
phase. (a-f) Untreated (closed squares), M1 at $681 \mathrm{mg} / \mathrm{kg}$ (closed circles), M1•ABZ once daily (open upright triangle), M1•ABZ twice daily (open upside down triangle). GraphPad Prism 6 was used to calculate the slopes of rapid tumor growth phases in both studies $(\mathbf{b}, \mathbf{e})$. Statistical differences between the slopes as compared to the UT group were elucidated $\left({ }^{*} p=0.01-0.05 ; *^{*} p=0.001-0.01 ; *^{* *} p<0.0001\right)$. The log-rank test $(\mathbf{c}, \mathbf{f})$ was performed to calculate statistical significances as compared to the UT group. 


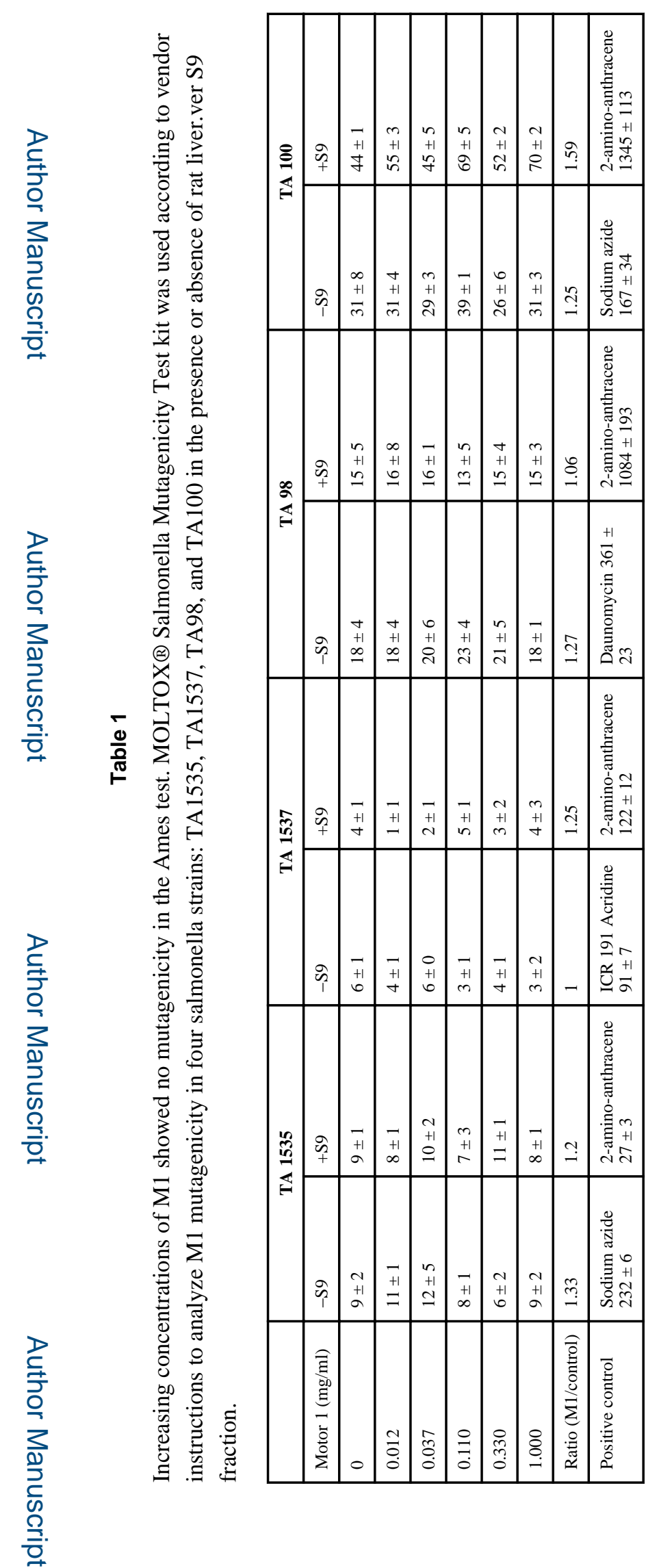

Mol Pharm. Author manuscript; available in PMC 2017 March 07. 
Table 2

Pharmacokinetic study of $\mathrm{M1} \bullet \mathrm{ABZ}$ revealed systemic ABZ and ABZSO bioavailability following IP administration

Bioavailability of ABZ was evaluated following one IV and IP administration of M1•ABZ (681 and $3.2 \mathrm{mg} /$ $\mathrm{kg}$ ). Blood was collected through cardiac puncture from 5 mice per time point per administration route.

Plasma concentrations of $\mathrm{ABZ}, \mathrm{ABZSO}$ and $\mathrm{ABZSO}_{2}$ were measured at 8 time points $(0.083,0.25,0.5,2,4$, 8, 16 and 24 h). GraphPad Prism 6 was used to determine the $\mathrm{C}_{\max }, \mathrm{t}_{\max }$ and AUC.

\begin{tabular}{|c|c|c|c|}
\hline IV Route & ABZ & ABZSO & ABZSO2 \\
\hline Cmax $(\mu \mathrm{g} / \mathrm{mL})$ & $2.47 \pm 0.37$ & $4.34 \pm 0.31$ & $0.50 \pm 0.09$ \\
\hline tmax $(\mathrm{h})$ & 0.083 & 0.5 & 2 \\
\hline AUC $(\mu \mathrm{g} \cdot \mathrm{h} / \mathrm{mL})$ & 0.81 & 14.30 & 2.94 \\
\hline IP Route & & & \\
\hline Cmax $(\mu \mathrm{g} / \mathrm{mL})$ & $1.56 \pm 0.64$ & $2.62 \pm 0.37$ & $0.41 \pm 0.07$ \\
\hline tmax $(\mathrm{h})$ & 0.083 & 0.25 & 2 \\
\hline AUC $(\mu \mathrm{g} \cdot \mathrm{h} / \mathrm{mL})$ & 0.63 & 6.15 & 2.38 \\
\hline Absolute Bioavailability $(\boldsymbol{\%})$ & $\mathbf{7 8}$ & $\mathbf{4 3}$ & $\mathbf{8 1}$ \\
\hline
\end{tabular}

